\title{
Effect of Suction Cycles and Suction Gradients on the Water Retention Properties of a Hard Clay
}

\author{
Liufeng Chen ${ }^{1,2}$ and Hua Peng ${ }^{1}$ \\ ${ }^{1}$ School of Civil and Architectural Engineering, Wuhan University, Wuhan 430072, China \\ ${ }^{2}$ College of Civil Engineering, Suzhou University of Science and Technology, Suzhou 215011, China \\ Correspondence should be addressed to Hua Peng; huapeng904@163.com
}

Received 14 May 2015; Accepted 22 November 2015

Academic Editor: Kisor K. Sahu

Copyright (c) 2015 L. Chen and H. Peng. This is an open access article distributed under the Creative Commons Attribution License, which permits unrestricted use, distribution, and reproduction in any medium, provided the original work is properly cited.

\begin{abstract}
The effect of suction cycles and suction gradients on a hard clay is investigated. The cylindrical samples of the hard clay are prepared to carry out the hydration and dehydration tests with different suction gradient and suction cycles. The results show that the suction gradient has little effect on the suction-water content relation, while the suction cycle has great effect on it, particularly the first cycle of hydration and dehydration. The apparent moisture diffusion coefficient of the hard clay has been identified by the use of a two-dimensional diffusion model. The moisture diffusion coefficient varies between $4.10^{-11} \mathrm{~m}^{2} / \mathrm{s}$ and $2.10^{-10} \mathrm{~m}^{2} / \mathrm{s}$ and it decreases during dehydration while the relative humidity is less than $85 \%$. The results also show that the suction cycles play little effect on the moisture diffusion coefficient.
\end{abstract}

\section{Introduction}

In Belgium, a hard clay has been considered as an ideal geological formation for high-level radioactive nuclear waste disposal in Belgium [1,2], because it has several favourable factors such as low permeability, plasticity, and high retention capacity for radionuclide. The hydromechanical behaviour of the host rock is one of the most important issues in the feasibility studies of the deep geological repository and many studies concerning coupled hydromechanical behaviour and unsaturated behaviour have been carried out [3-5]. Earlier studies show that the mechanical behaviour of clay strongly depends on water content $[6,7]$ and dehydration and hydration can induce a chemical-physical reaction and change the microstructure of clay and degrade the properties of clay [810]. The excavation stage and the open-drift stage of a nuclear waste repository could last a few decades during which the ventilation and temperature conditions will change [11]. The hydromechanical properties of clay could be changed due to cyclic moisture variation. The studies of Wang et al. in 2013 [10] show that different suction gradients play a notable effect on the microstructure of the COx argillaceous rock and larger suction gradients create more microcracks in the clayey matrix than smaller suction gradient during the same suction range. The microstructure change could affect the water retention properties of the material. The purpose of this study was to investigate the effect of suction cycles and suction gradients on the water retention properties of Boom clay.

\section{Material and Methods}

2.1. Material and Sample Preparation. In this study, the hydration and dehydration tests have been performed on Boom clay that is a plastic clay. Boom clay contains an average of $55 \%$ clay minerals including illite and smectite, $20 \%-25 \%$ quartz, 5\%-10\% feldspar, and the small content of pyrite $(<5 \%)$ and calcite $(<5 \%)[12]$. The dry density of the material varies between 1.6 and $1.7 \mathrm{~g} / \mathrm{cm}^{3}$ [3]. The total porosity of Boom clay is between $36 \%$ and $40 \%[1,12]$ and the hydraulic conductivity is around $10^{-12} \mathrm{~m} / \mathrm{s}$. Young's modulus of the Boom clay is around $300 \mathrm{MPa}$ and the uniaxial compression strength is about $2 \mathrm{MPa}$.

The cylindrical sample with a diameter of $36 \mathrm{~mm}$ and a length of $10 \mathrm{~mm}$ approximately was machined from the cores extracted from the Praclay gallery in the $\mathrm{Mol}$ underground research laboratory at a depth of $223 \mathrm{~m}$ in Belgium. Special care was taken to assure that the sample was in saturated 
TABLE 1: Four different dehydration and hydration paths.

\begin{tabular}{ll}
\hline Type & Dehydration and hydration path \\
\hline A & Saturated state $\rightarrow 98 \% \rightarrow 90 \% \rightarrow 85 \% \rightarrow 81 \% \rightarrow 75 \% \rightarrow 59 \% \rightarrow 43 \% \rightarrow 32.5 \% \rightarrow 11 \% \rightarrow 32.5 \% \rightarrow 43 \% \rightarrow$ \\
& $59 \% \rightarrow 75 \% \rightarrow 81 \% \rightarrow 85 \% \rightarrow 90 \% \rightarrow 98 \%$ \\
\hline B & Saturated state $\rightarrow 98 \% \rightarrow 75 \% \rightarrow 32.5 \% \rightarrow 75 \% \rightarrow 98 \% \rightarrow 75 \% \rightarrow 32.5 \% \rightarrow 75 \% \rightarrow 98 \% \rightarrow 75 \% \rightarrow 32.5 \% \rightarrow$ \\
& $75 \% \rightarrow 98 \%$ \\
C & Saturated state $\rightarrow 98 \% \rightarrow 81 \% \rightarrow 59 \% \rightarrow 11 \% \rightarrow 98 \% \rightarrow 81 \% \rightarrow 59 \% \rightarrow 11 \% \rightarrow 59 \% \rightarrow 81 \% \rightarrow 98 \% \rightarrow$ \\
& $81 \% \rightarrow 59 \% \rightarrow 11 \%$. \\
D & Saturated state $\rightarrow 98 \% \rightarrow 75 \% \rightarrow 32.5 \% \rightarrow 75 \% \rightarrow 98 \% \rightarrow 75 \% \rightarrow 32.5 \% \rightarrow 75 \% \rightarrow 98 \% \rightarrow 75 \% \rightarrow 32.5 \% \rightarrow$ \\
& $75 \% \rightarrow 98 \%$.
\end{tabular}

state. The measurements show that the tested samples had an average water content of $25 \%$ at the initial state and dry density of $1.63 \mathrm{~g} / \mathrm{cm}^{3}$.

2.2. Experimental Method. In order to determine the water retention properties of Boom clay, the suction was imposed by controlling the relative humidity in an airtight container. The relative humidity can be imposed by the use of supersaturated saline solution, which creates a fixed vapour pressure in a sealed container. As shown by Delage et al. in 1998 [13], different values of relative humidity corresponding to the saline solution are listed and they firmly depend on the temperature. The tested samples were placed into the desiccators containing saturated saline solutions at their bottom. Different supersaturated saline solutions $\left(\mathrm{LiCl}, \mathrm{CaCl}_{2} \cdot 6 \mathrm{H}_{2} \mathrm{O}\right.$, $\mathrm{K}_{2} \mathrm{CO}_{3} \cdot 2 \mathrm{H}_{2} \mathrm{O}, \mathrm{NaBr}, \mathrm{NaCl},\left(\mathrm{NH}_{4}\right)_{2} \mathrm{SO}_{4}, \mathrm{KCl}, \mathrm{ZnSO}_{4} \cdot 7 \mathrm{H}_{2} \mathrm{O}$, and $\mathrm{CuSO}_{4} \cdot 5 \mathrm{H}_{2} \mathrm{O}$ ) were chosen to cover a large range of relative humidity from $98 \%$ to $11 \%$. The corresponding suction at $25^{\circ} \mathrm{C}$ varies from 2.76 to $301.51 \mathrm{MPa}$, following the Kelvin law [13]:

$$
P_{c}=-\frac{R T}{M_{w} V_{w}} \ln \left(\frac{P}{P_{0}}\right)=-\frac{R T}{M_{w} V_{w}} \ln \left(\frac{H R}{100}\right) .
$$

$P_{c}$ is the suction, equal to the absolute difference between the air and water pressures; $R$ is the constant of perfect gases $\left(R=8.3143 \mathrm{~J} \cdot \mathrm{mol} \cdot \mathrm{K}^{-1}\right)$; $T$ is the absolute temperature $\left(T=298 \mathrm{~K}\right.$ at $\left.25^{\circ} \mathrm{C}\right) ; M_{w}$ is the molar masse of water $\left(M_{w}=18.016 \mathrm{~g} \cdot \mathrm{mol}^{-1}\right) ; V_{w}$ is specific volume of water $\left(V_{w}=\right.$ $\left.0.99565 \mathrm{~g} \cdot \mathrm{cm}^{-3}\right) ; P$ is the partial water vapour pressure; and $P_{0}$ is the fact that, at state saturated, their ration is the relative humidity. Note that all the tests are carried out at a constant environment temperature.

The saturated saline solutions used and the corresponding suctions/relative humidity at $20^{\circ} \mathrm{C}$ have been presented by Delage et al. in [13]. Note that all the tests are carried out at a constant environment temperature $\left(25^{\circ} \mathrm{C}\right)$.

2.3. Test Program. To study the effects of suction gradients and suction cycles on water retention properties of Boom clay, four different dehydration and hydration paths were programmed as shown in Table 1. In order to obtain the representative results, a series of samples are submitted to a same hydration or dehydration path. Path A was performed on the six samples (A1-A6) with different heights and it consisted of one cycle of dehydration and hydration with small suction gradient. Path B was performed on five samples (B1-B5) and it consists of two drying/wetting cycles with small suction gradient. Path $\mathrm{C}$ was performed on eight samples (C1-C8) and it is composed of two and a half cycles of hydration and dehydration with large suction gradient. Path D was performed on eight samples (D1-D8) and it consists of three drying/wetting cycles with larger suction gradient. Because of the low permeability of Boom clay, each moisture stage lasted more than one week to reach a stable state. Note that more than five samples were simultaneously tested following the same hydration and dehydration paths to get better confidence in the results.

When the samples reached mass stabilization, the sample was weighted rapidly and then placed in the desiccator to subject to the next hydric loading. Once the whole hydration and dehydration cycles finished, the tested samples were dried in the oven at $105^{\circ} \mathrm{C}$ to determine the dry weight. The volume of the sample was measured by immersing the waxed samples into water.

\section{Experimental Results}

3.1. Water Retention Curves. The successive samples weights $(M)$ at the moisture equilibrium were measured and the corresponding water contents $(w)$ were thus determined by comparing the measured weight $(M)$ with the dried weight $\left(M_{d}\right)$ obtained at the end of the test: $w=\left(M-M_{d}\right) / M_{d}$. All the results concerning the water content show that the samples submitted to the same hydration and dehydration path have close water content change during each moisture phase as shown in Figure 1 which illustrates the water content evolution of the three samples (A1, A2, and A3) following path A. Therefore, the water content evolution observed of the Boom clay in centimetre should be representative to study the water retention curves of the material. We will present only the results of the samples $\mathrm{A} 1, \mathrm{~B} 1, \mathrm{C} 1$, and $\mathrm{D} 1$ in order to focus on the effect of suction cycles and suction gradients on the water content properties.

The gravitational water content versus suction of the samples A1, B1, C1, and D1 is plotted in Figures 2(a), 2(b), 2(c), and 2(d), respectively. Similar to the results of Bernier et al. in 1997 [3] and Li et al. in 2006 [1], the water retention curves show that the water content decreases nonlinearly with the increase of suction. The water content variation is relatively larger than that obtained by CIEMAT [3] and close to the results obtained by the researchers of Universitat Politècnica 


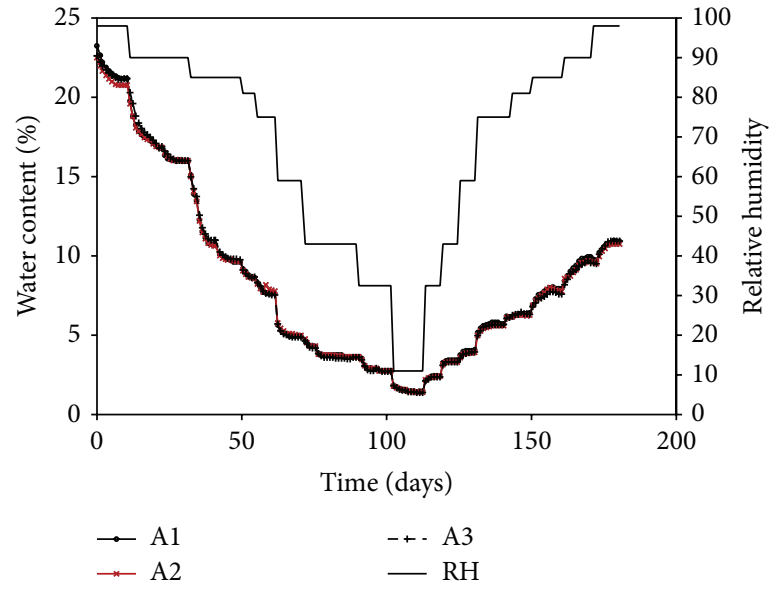

Figure 1: Hydration and dehydration path and the corresponding water content evolution of the samples A1, A2, and A3.
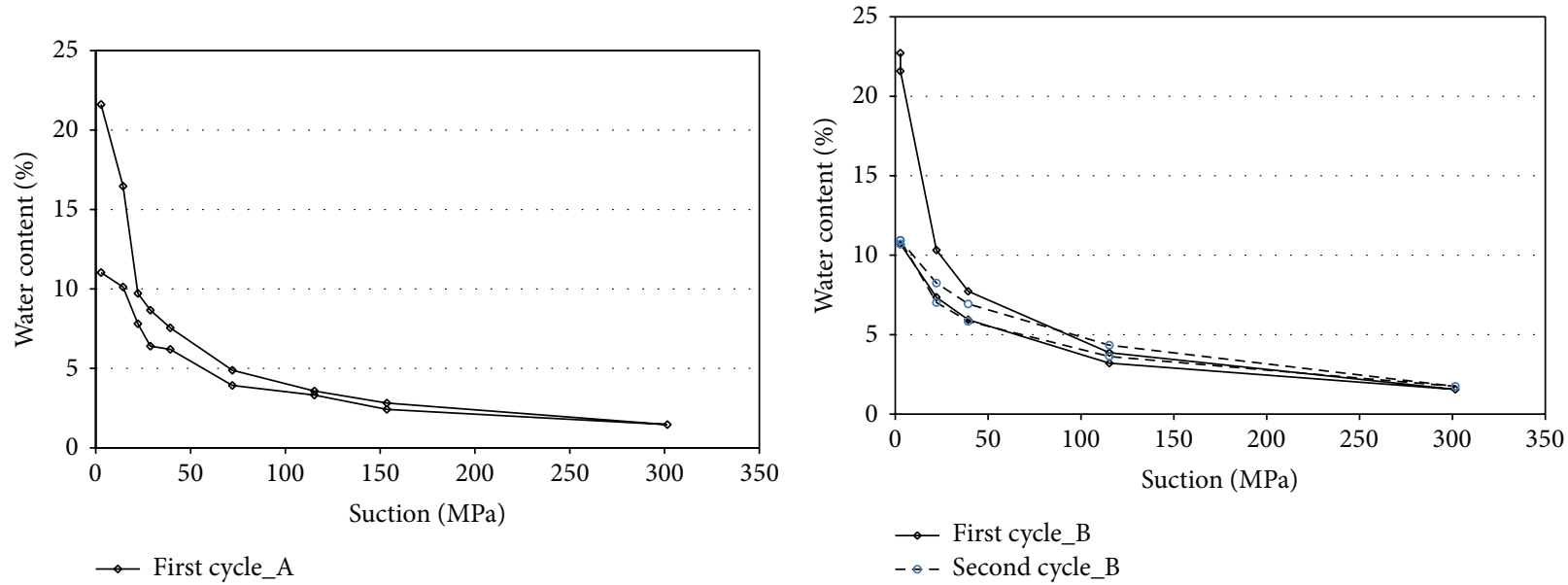

(a)

(b)
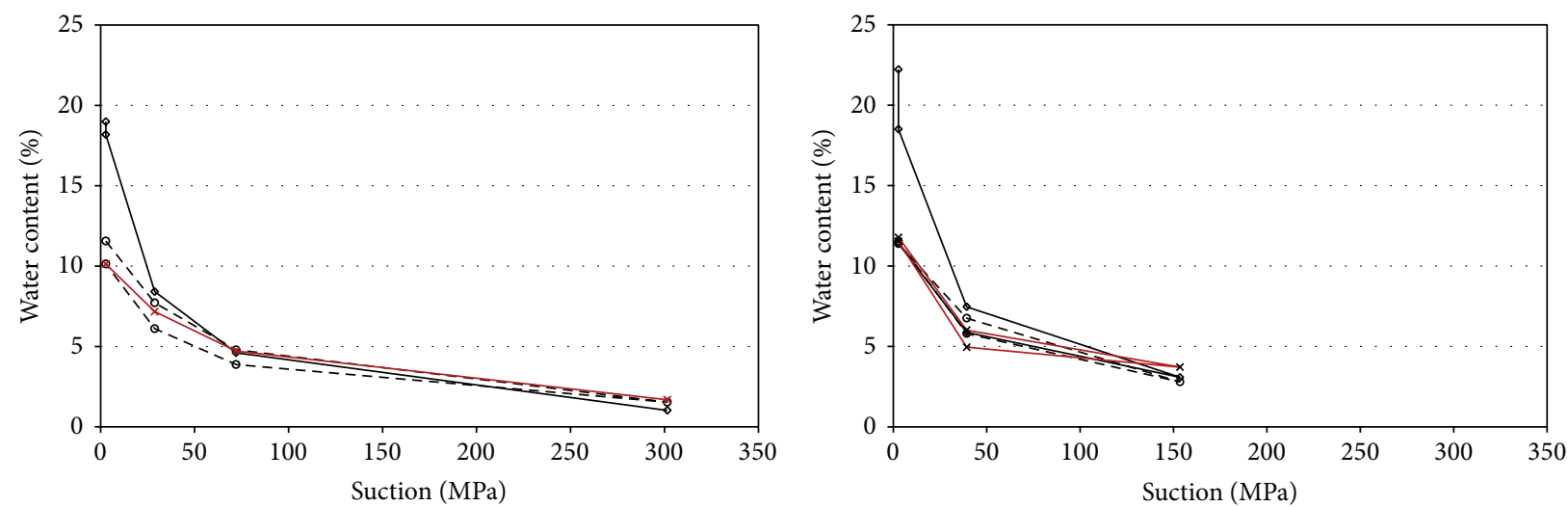

$\rightarrow$ First cycle_C

- $\bullet$ - Second cycle_C

* Third cycle_C

$\rightarrow$ First cycle_D

$-\bullet$ - Second cycle_D

$\rightarrow$ Third cycle_D

(c)

(d)

FIgURE 2: The water retention curves of the samples A1, B1, C1, and D1. 


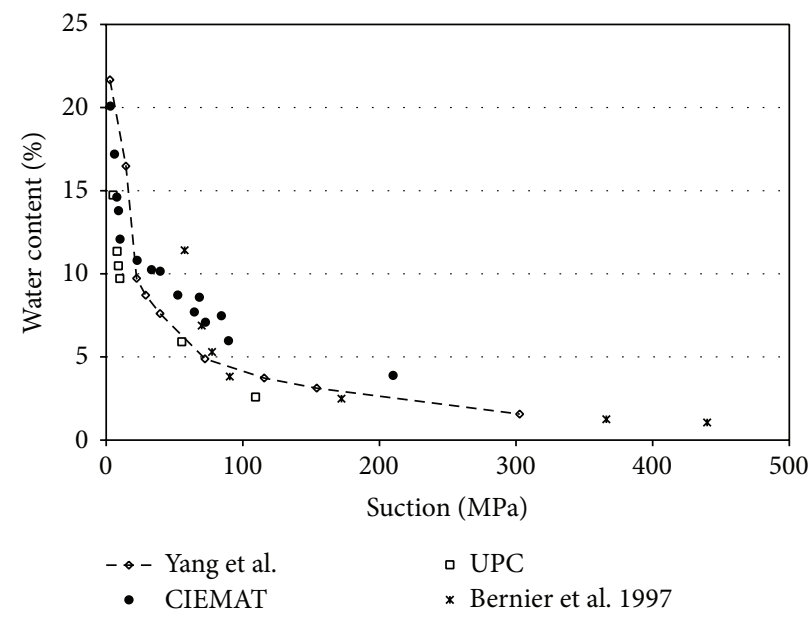

FIGURE 3: The comparison of the water retention curves of different studies.

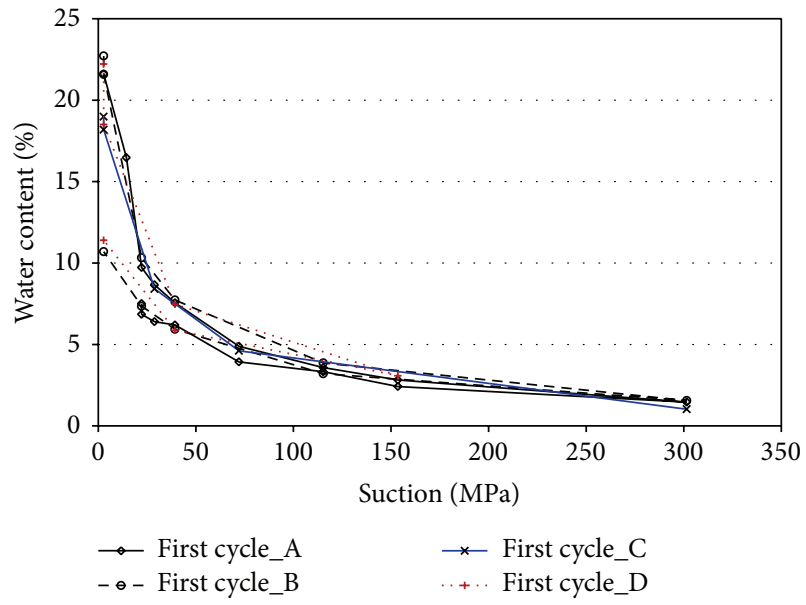

(a)

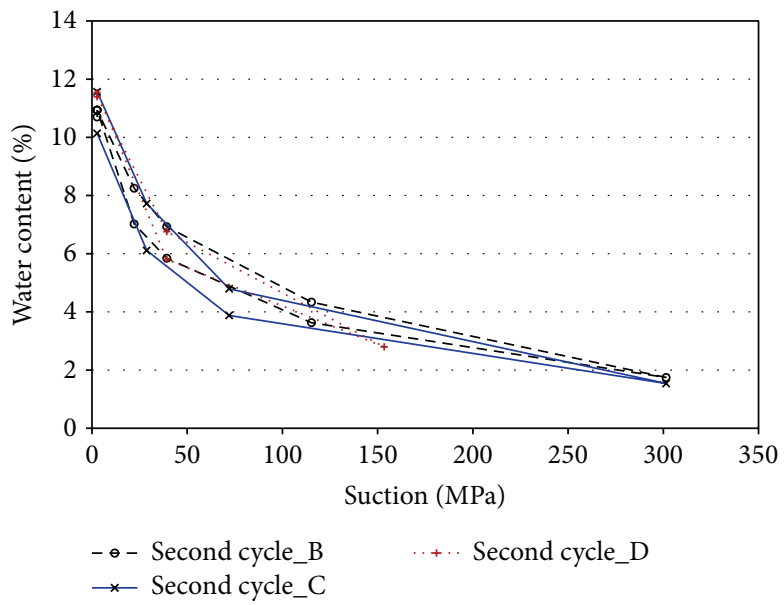

(b)

FIGURE 4: (a) Effect of suction gradient on the water retention curves during the first hydric cycle and (b) the second hydric cycle.

de Catalunya (UPC) (Figure 3). The water content decreases greatly during the first desaturation and it losses more than $10 \%$ when the suction increases to $29 \mathrm{MPa}$ corresponding to a relative humidity of $81 \%$. The large variation of the water content should be related to both the initial state and the pore size distribution of Boom clay. During the first dehydration, the initial state of the sample is fully saturated and the continuous water will be vapoured and it will induce the shrinkage of Boom clay and lead to a large variation of water content. The first cycle and the second cycle of dehydration and hydration of the four samples (A1, B1, C1, and D1) are, respectively, regrouped in Figures 4(a) and 4(b), which show that the water content of the samples at the same suction level is very close and there is little effect of the suction gradient on the water retention curves. Figures 2(b), 2(c), and 2(d) show also that there is large difference between the first hydric cycle and the second one. However, there is small difference between the second hydric cycle and the third hydric cycle. Moreover, the water content is nearly reversible after the second and third hydric cycle
(Figure 2(d)). Therefore, suction cycles play an important role on the water retention curves, mainly the first dehydration and hydration cycle. The little effect of suction gradient on the water retention properties should be related to small microstructure change during hydration and dehydration which is different from the COx argillaceous rock. The effect of suction cycle on the water retention properties should be mainly related to the pore size distribution as Bernier et al. in 1997 [3] and Coussy in 2010 [15] indicated.

3.2. Moisture Diffusion Coefficient. The dehydration and hydration tests with different paths lasted more than six months. The long test duration should be firmly related to the transfer moisture properties. In fact, the moisture transfer process is complex and it depends on the relative humidity level. At high relative humidity, the capillary phase remains continuous and the moisture transfer is governed by the capillary forces; when relative humidity decreases, the liquid water and the gas (vapour and air) coexist and the moisture transfer is controlled by the exchange between 


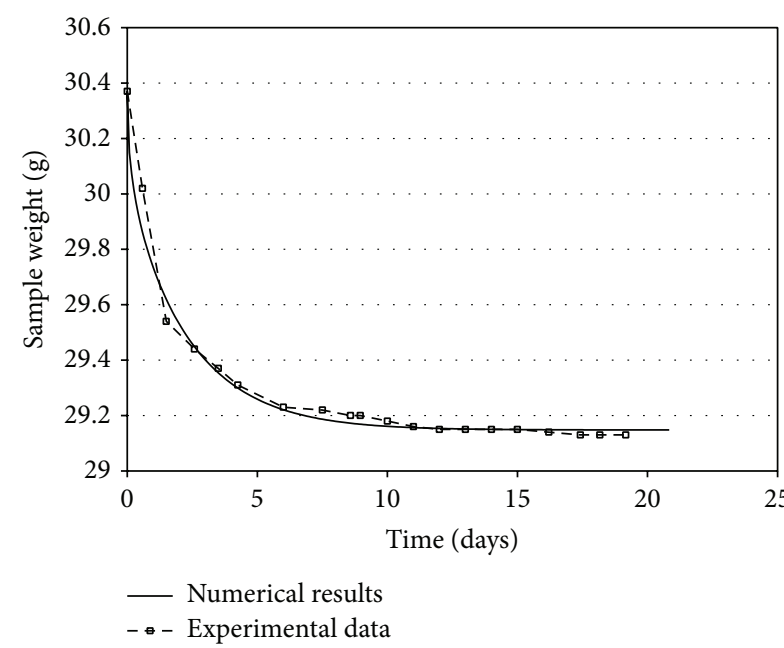

(a)

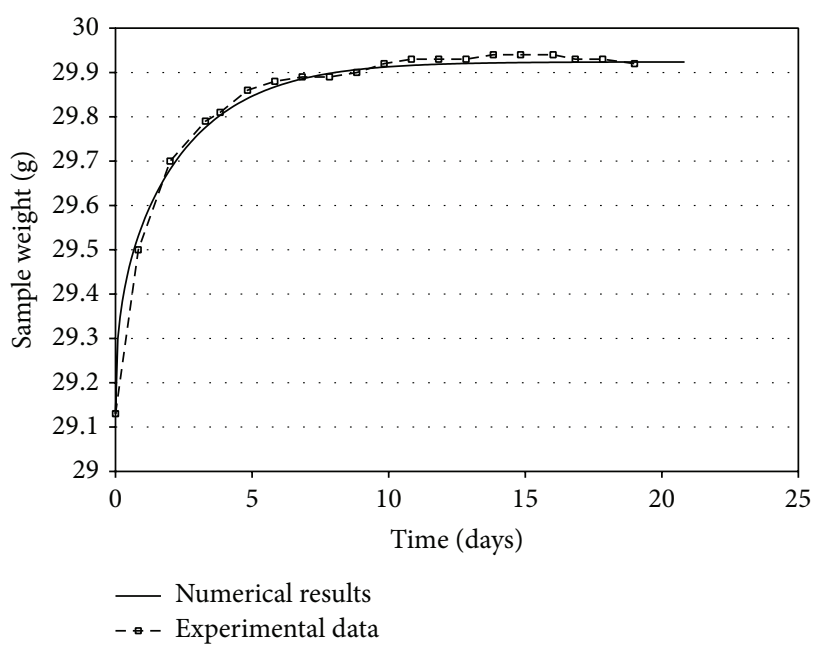

(b)

Figure 5: (a) Experimental results and the numerical prediction of the weight evolution of the sample D1 during dehydration while the relative humidity (RH) decreases from $75 \%$ to $32 \%$ (b) and during hydration with the increase of RH from $32 \%$ to $75 \%$.

evaporation and condensation; at low relative humidity, the pores are mainly occupied by gas and the moisture transfer is controlled by vapour diffusion [14]. In this study, the apparent moisture diffusion coefficient is used to characterize the transfer properties of Boom clay. Assuming the validity of the mass conservation law and Fick's law [15], the moisture transfer of the cylindrical sample of Boom clay can be expressed using a macroscopic model in two dimensions to simulate the moisture diffusion in the radial direction and the vertical direction:

$$
\frac{\partial m_{e}}{\partial t}=D_{e}\left(\frac{\partial^{2} m_{e}}{\partial r^{2}}+\frac{1}{r} \frac{\partial m_{e}}{\partial r}+\frac{\partial^{2} m_{e}}{\partial z^{2}}\right) .
$$

With $0 \leq r<a, 0<z<l$ for $t>0$, where $m_{e}$ is the volumetric mass water content $\left(\mathrm{kg} \cdot \mathrm{m}^{-3}\right)$ defined as $m_{e}=$ $\rho_{e} \phi S_{r}\left(\mathrm{~kg} \cdot \mathrm{m}^{-3}\right) ; \rho_{e}$ is the water density; $\phi$ is porosity; $S_{r}$ is the saturation degree; $a$ is the radius of sample $(m)$ and $l$ is the length $(m)$; and $D_{e}$ is the apparent moisture diffusion coefficient $\left(\mathrm{m}^{2} \cdot \mathrm{s}^{-1}\right)$.

While the initial conditions (porosity, geometric parameters) and boundary conditions (initial and final saturation) are given, the numerical solution of (2) can be obtained by means of the finite difference time domain method. The moisture equilibrium time only depends on $D_{e}$. The apparent moisture diffusion coefficient is determined by searching an optimal parameter $D_{e}$ to minimize the difference between the experimental masse evolution and the numerical solution of (2). Figure 5(a) illustrates the experimental weight evolution of the sample D1 when the relative humidity decreased from $75 \%$ to $32 \%$ to compare with its numerical solution with a coefficient of diffusion of $1.410^{-10} \mathrm{~m}^{2} \cdot \mathrm{s}^{-1}$. Figure 5(b) illustrates the case of hydration. The numerical prediction data fits well with the experimental results. Most of the hydric phases are analysed and the moisture diffusion coefficient of the sample D1 varies from $410^{-11} \mathrm{~m}^{2} \cdot \mathrm{s}^{-1}$ to $210^{-10} \mathrm{~m}^{2} \cdot \mathrm{s}^{-1}$. It is much smaller at the high relative humidity of $98 \%$ than at the lower humidity level as shown in Figures 6(a) and 6(b) which gives evidence also of the little effect of hydration and dehydration cycle on moisture diffusion coefficient. In fact, the moisture diffusion coefficient is firmly related to the water permeability, which decreases with the diminution of the relative humidity. The results of this study confirm it as shown in Figure 6, even if the apparent diffusion coefficient varies very little during hydration and dehydration when the relative humidity is less than $85 \%$.

\section{Conclusions}

In order to study the effect of suction cycles and suction gradients on the water retention properties of the hard clay, a series of samples are prepared to carry out dehydration and hydration tests by means of suction controlled technique. Four hydric paths with different suction cycles and suction gradients are programmed and each hydric test has lasted more than six months. The results concerning water content show that the samples following the same hydric path have a very close water content variation during the same suction change and suction gradient has little effect on the suction water content relation, while the suction cycle has great effect on it, particularly the first cycle of hydration and dehydration will change much the suction-water content relation.

Because of the very low permeability, each hydric phase during dehydration and hydration lasted more than one week. The moisture transfer properties of Boom clay were quantified by the use of a two-dimensional diffusion model. The apparent moisture diffusion coefficient of Boom clay varies between $410^{-11} \mathrm{~m}^{2} / \mathrm{s}$ and $210^{-10} \mathrm{~m}^{2} / \mathrm{s}$. It decreases during dehydration while the relative humidity is less than $85 \%$. The moisture diffusion coefficient is relatively small when the relative humidity is close to $98 \%$ and it is about 4 $10^{-11} \mathrm{~m}^{2} / \mathrm{s}$. The results show also that the suction cycles play little effect on the moisture diffusion coefficient. 


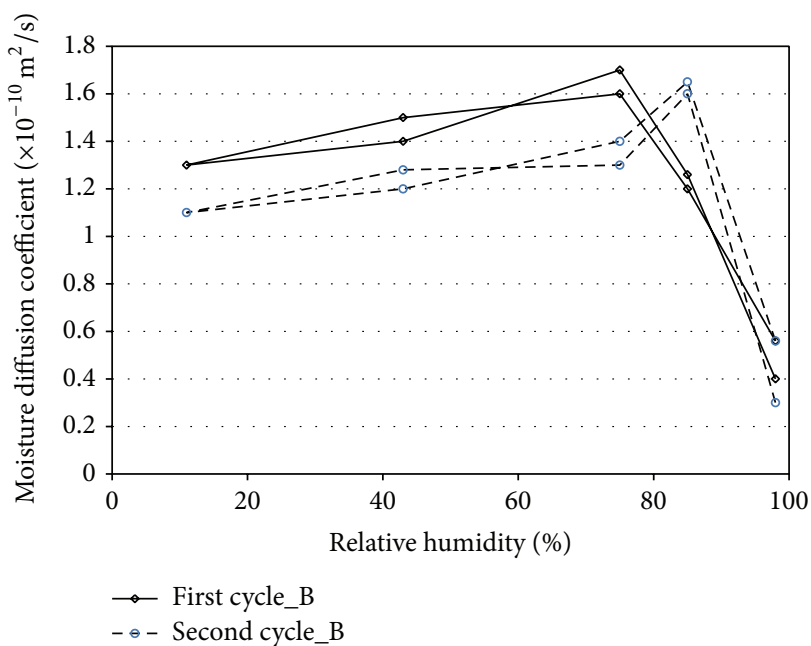

(a)

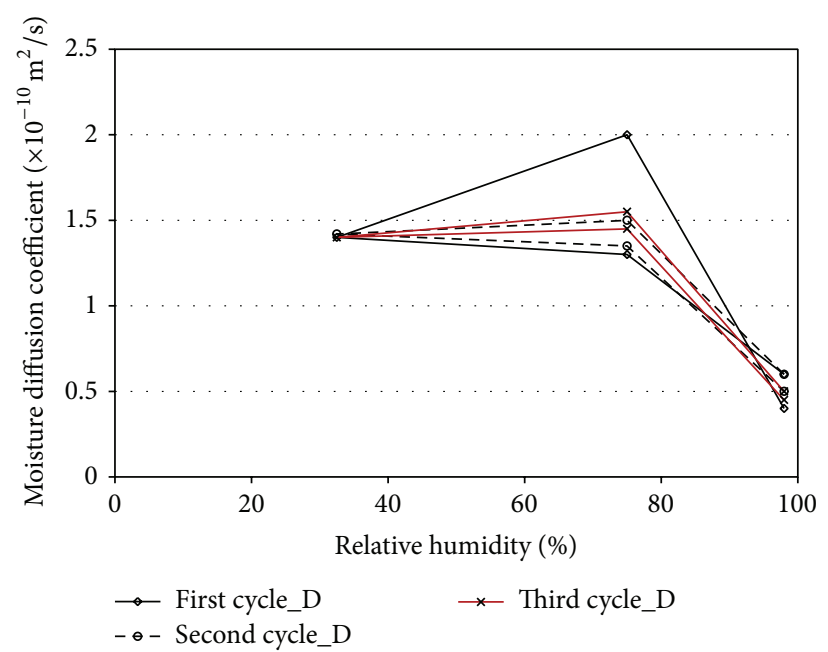

(b)

FIGURE 6: (a) The apparent moisture diffusion coefficient of the sample B1 (b) and the sample D1.

\section{Conflict of Interests}

The authors declare that they have no conflict of interests.

\section{Acknowledgments}

The authors gratefully acknowledge the support of the National Natural Science Foundation of China (Grant nos. 51379200, 51225902). The authors gratefully thank Dr. Diansen Yang for the paper preparation and Professor Weizhong Chen for the helpful discussion.

\section{References}

[1] X. L. Li, W. Bastiaens, and F. Bernier, "The hydromechanical behaviour of the Boom Clay observed during excavation of the connecting gallery at Mol site," in Proceedings of EUROCK2006Multiphysics Coupling and Long Term Behaviour in Rock Mechanics, Liege, Belgium, pp. 467-472, Balkema, Rotterdam, The Netherlands, 2006.

[2] H.-D. Yu, W.-Z. Chen, S.-P. Jia, J.-J. Cao, and X.-L. Li, "Experimental study on the hydro-mechanical behavior of Boom clay," International Journal of Rock Mechanics and Mining Sciences, vol. 53, pp. 159-165, 2012.

[3] F. Bernier, G. Volckaert, E. Alonso, and M. Villar, "Suctioncontrolled experiments on Boom clay," Engineering Geology, vol. 47, no. 4, pp. 325-338, 1997.

[4] F. Collin, X. L. Li, J. P. Radu, and R. Charlier, "Thermo-hydromechanical coupling in clay barriers," Engineering Geology, vol. 64, no. 2-3, pp. 179-193, 2002.

[5] M. Wan, P. Delage, A. M. Tang, and J. Talandier, "Water retention properties of the Callovo-Oxfordian claystone," International Journal of Rock Mechanics and Mining Sciences, vol. 64, pp. 96-104, 2013.

[6] Q. T. Pham, F. Valès, L. Malinsky, D. N. Minh, and H. Gharbi, "Effects of desaturation-resaturation on mudstone," Physics and Chemistry of the Earth, vol. 32, no. 8-14, pp. 646-655, 2007.

[7] D. S. Yang, M. Bornert, S. Chanchole, H. Gharbi, and P. Valli, "Dependence on moisture content of elastic properties of argillaceous rocks investigated with optical full-field strain measurement techniques," International Journal of Rock Mechanics and Mining Sciences, vol. 54, pp. 53-62, 2012.

[8] E. E. Alonso, J. Vaunat, and A. Gens, "Modelling the mechanical behaviour of expansive clays," Engineering Geology, vol. 54, no. 1-2, pp. 173-183, 1999.

[9] J. Vaunat and A. Gens, "Analysis of the hydration of a bentonite seal in a deep radioactive waste repository," Engineering Geology, vol. 81, no. 3, pp. 317-328, 2005.

[10] L. L. Wang, M. Bornert, S. Chanchole et al., "Micro-scale experimental investigation of the swelling anisotropy of the Callovo-Oxfordian argillaceous rock," Clay Minerals, vol. 48, no. 2, pp. 391-402, 2013.

[11] C.-F. Tsang, F. Bernier, and C. Davies, "Geohydromechanical processes in the Excavation Damaged Zone in crystalline rock, rock salt, and indurated and plastic clays-in the context of radioactive waste disposal," International Journal of Rock Mechanics \& Mining Sciences, vol. 42, no. 1, pp. 109-125, 2005.

[12] C. Coll, Endommagement des roches argileuses et perméabilité induite au voisinage d'ouvrage souterrains [Ph.D. thesis], Université Joseph Fourier-Grenoble 1, Grenoble, France, 2005.

[13] P. Delage, M. D. Howat, and Y. J. Cui, "The relationship between suction and swelling properties in a heavily compacted unsaturated clay," Engineering Geology, vol. 50, no. 1-2, pp. 31-48, 1998.

[14] V. Baroghel-Bouny, "Water vapour sorption experiments on hardened cementitious materials. Part II: essential tool for assessment of transport properties and for durability prediction," Cement and Concrete Research, vol. 37, no. 3, pp. 438-454, 2007.

[15] O. Coussy, Mechanics and Physics of Porous Solids, John Wiley \& Sons, 2010. 

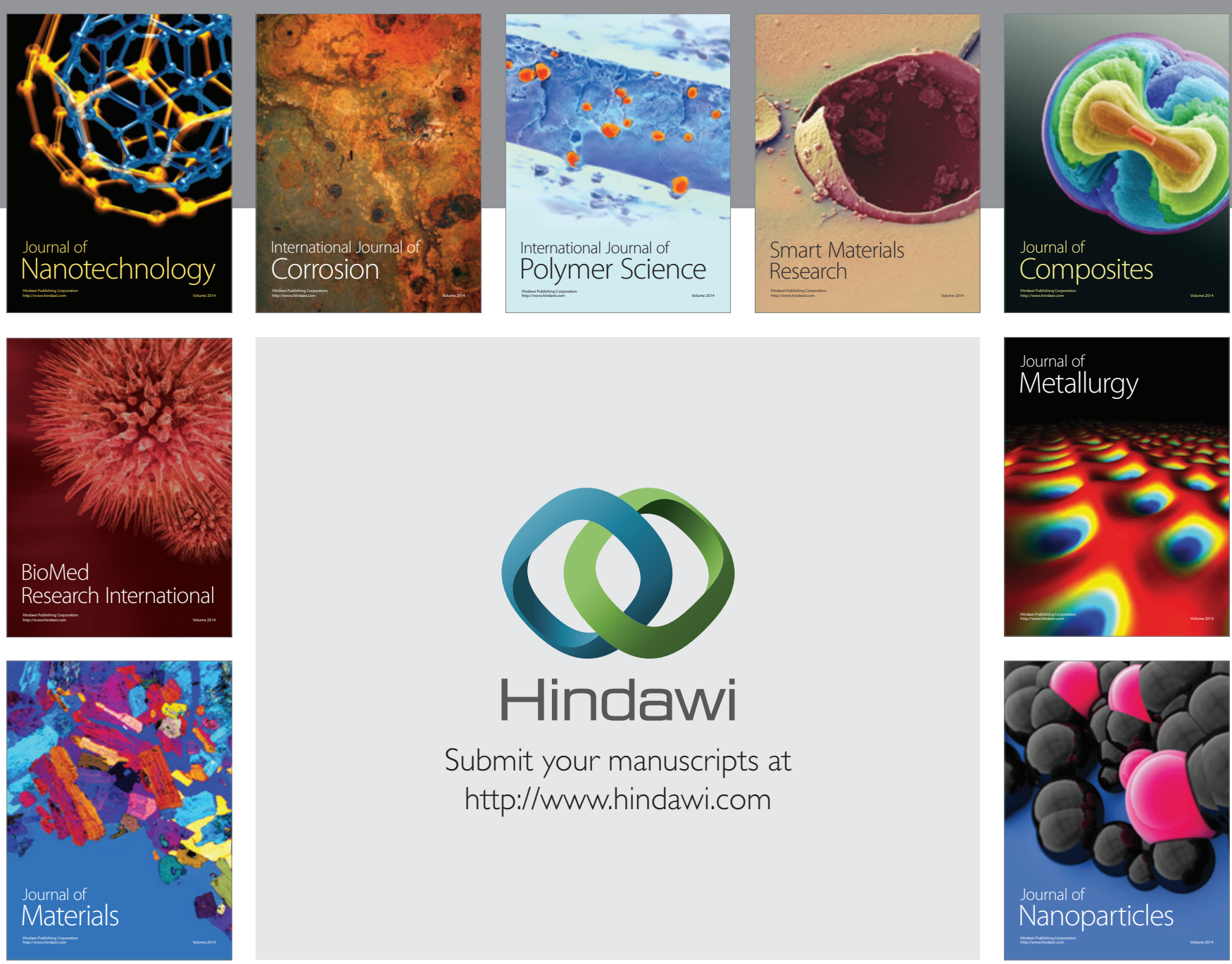

Submit your manuscripts at http://www.hindawi.com
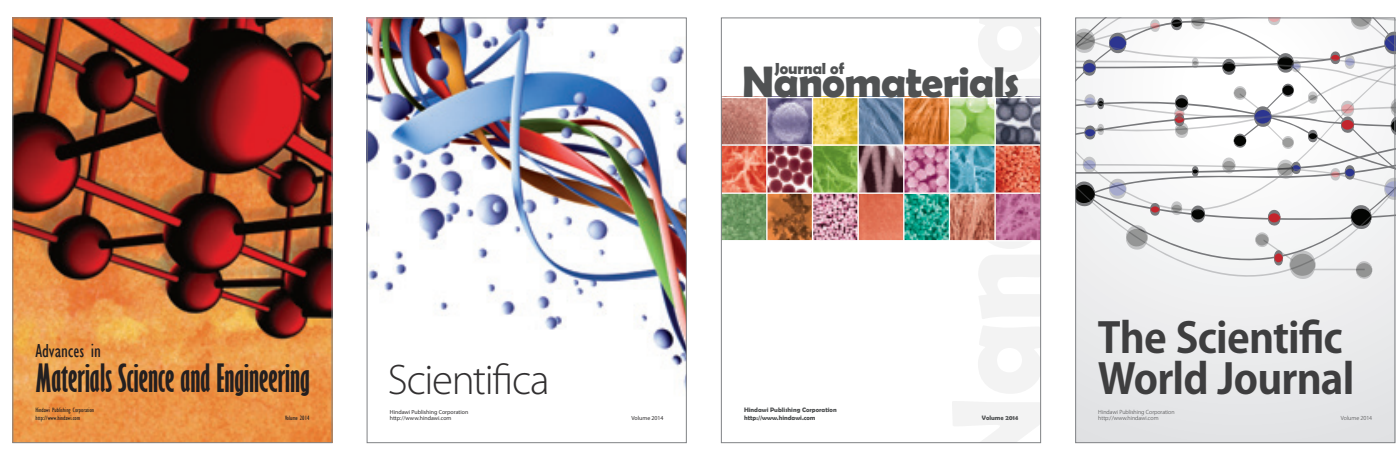

\section{The Scientific World Journal}
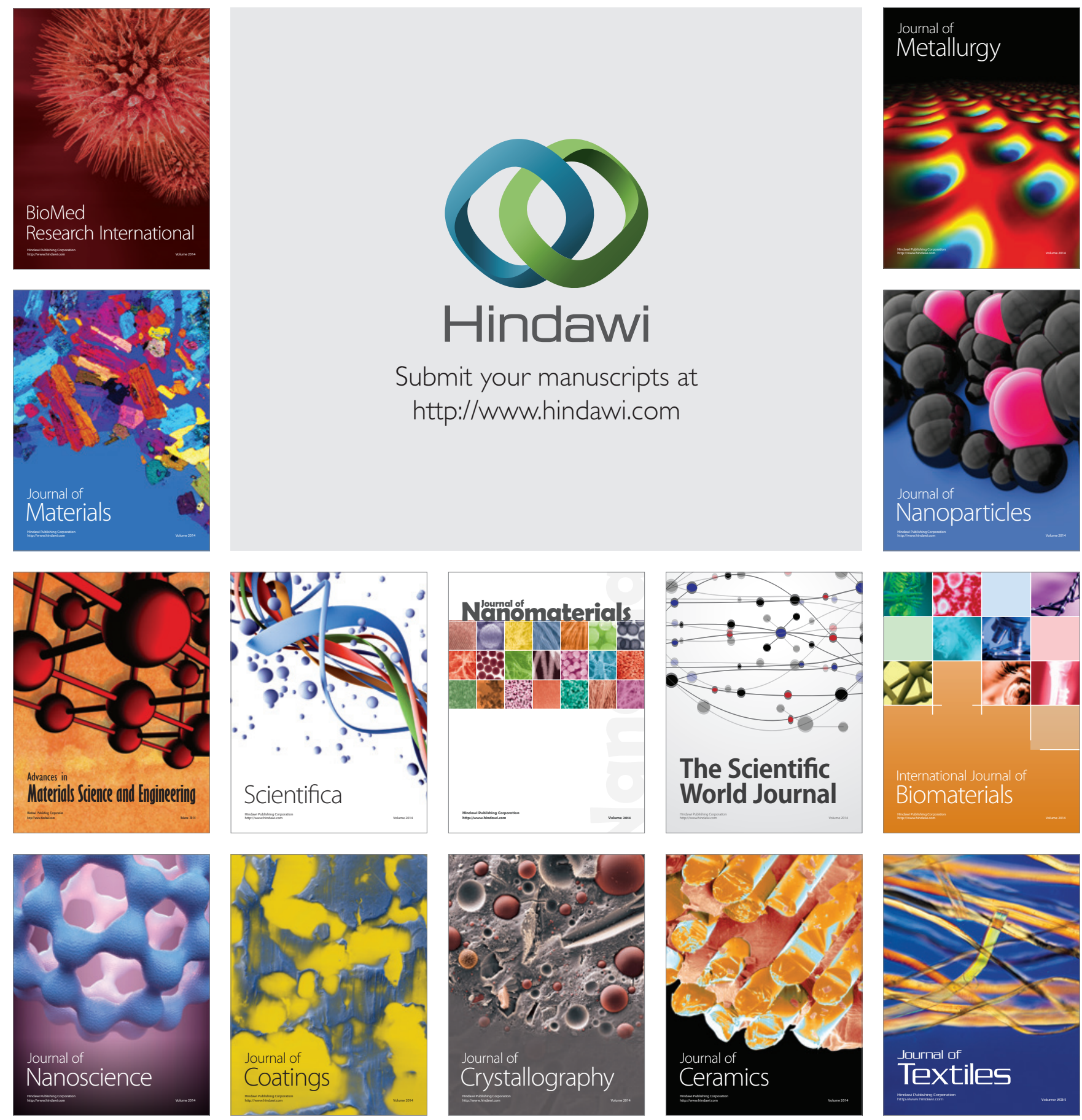